Fifth International Conference on Sustainable Construction Materials and

Technologies. http://www.claisse.info/Proceedings.htm

\title{
LADLE FURNACE SLAG AS CEMENT REPLACEMENT IN MORTAR MIXES
}

Amaia Santamaria ${ }^{a, *}$, Vanesa Ortega-Lopez ${ }^{\mathrm{b}}$, Marta Skaf ${ }^{\mathrm{c}}$, Veronica García ${ }^{\mathrm{d}}$, Juan J. Gaitero $^{\mathrm{d}}$, Jose T. San-Jose ${ }^{\mathrm{e}}$, Javier J. González

${ }^{a}$ Department of Mechanical Engineering, University of the Basque Country UPV/EHU. Paseo Rafael Moreno Pitxitxi 2 - 48013 Bilbao, Spain

${ }^{\mathrm{b}}$ Department of Civil Engineering, University of Burgos UBU. Calle Villadiego, s/n 09001 Burgos, Spain

${ }^{c}$ Department of Construction, University of Burgos UBU. Calle Villadiego, s/n - 09001 Burgos, Spain

d Sustainable Construction Unit, TECNALIA. Calle Geldo, Parque Tecnológico de Bizkaia (Edificio 700) - 48160 Derio, Spain

e Department of Metallurgical Engineering and Materials Science, University of the Basque Country UPV/EHU. Plaza Ingeniero Torres Quevedo, 1 - 48013 Bilbao, Spain

*Corresponding author: amaia.santamaria@ehu.es

\begin{abstract}
.
Ladle furnace slag is a significant by-product of the steel-making industry. Depending on the production conditions, the steel-refining process yields two types of basic slag, which are either low or high in silica and alumina, depending on the fluxing temperature and the saturation method. The present investigation focuses on the feasibility of producing mortar mixes, by incorporating both ladle furnace slag types in partial replacement of Portland cement, in amounts of 10\%, 20\%, 30\% and $40 \%$ by weight. The fresh and hardened properties of the mortars are analysed, and the hydraulic properties of both types of ladle slag are evaluated. These kinds of by-products are affordable applications in mortars that add useful qualities to the building materials. Their use in partial replacement of cement contributes to global sustainability through the reduction of cement consumption, thereby reducing greenhouse gas emissions.
\end{abstract}

Keywords: Ladle Furnace (LF) Slag; Supplementary cementitious materials (SCM); Mortar mixes; Mechanical behaviour; Shrinkage. 


\section{INTRODUCTION}

The construction industry is a leading industry in the Spanish economy. The most widely employed building material in that sector is concrete. Cement is the raw material with the largest carbon footprint in the manufacture of concrete. The use of Supplementary Cementitious Materials (SCMs) has become common practice in efforts to guide the industry towards more sustainable production methods. SCMs are mainly in the form of by-products from industrial processing (Güneyisi, Gesoğlu et al. 2015, Felekoglu, Tosun et al. 2006).

Waste materials known as steel slag are by-products generated in the manufacture of steel. Depending on the furnace type used in the production of steel, the steel slag will have different properties. Most slag types are of similar composition, but any differences between them can be significant when considering their reuse in cement. The chemical composition and the physical properties of Ground Granulated Blast Furnace slag are suitable for its use as a SCM and it has in fact been used in this way over several decades. Electric arc furnace slag is another slag type that can be found in recent construction works (Faleschini, Hofer et al. 2017), in replacement of conventional aggregates. Examples may be found in the Basque Country, for example, of its use in the construction of concrete blocks for various sea-ports (García Mochales 2016).

However, Ladle Furnace (LF) slag is still disposed of in dumping sites. This slag comes from the secondary or basic steel refinement process, which mainly consists of desulphurization; depending on the saturation method of the melting flux, ladle furnace slag can be divided into two types, silica saturated ladle furnace slag, and alumina saturated ladle furnace slag. Almost $80 \mathrm{~kg}$ of ladle furnace slag is generated per ton of refined steel.

This slag usually presents a dusty appearance, due to spontaneous disintegration of its mass during cooling. Its disintegration is mainly due to the allotropic transformation of calcium silicate beta into calcium silicate gamma.

Scanning electron microscopy of the slag showed that the physical characteristics of its dusty particles are in the form of single polyhedral crystals and irregular aggregates formed of polyhedral crystals with sharp contours that are porous and hollow.

As confirmed in the literature (Setién, Hernández et al. 2009), 80\% of the mass of LF slag consists of calcium silicates and calcium aluminates that also contain magnesium, and other cations. The remainder of its mass consists of sulphur compounds, small amounts of metallic iron, detachable by magnetic methods, and traces of titanium, manganese, sodium and potassium.

Free lime and free magnesia can also be found in LF slags. The presence of these expansive compounds has caused problems in the past when the slags were used with insufficient knowledge of their working properties. Figure 1 shows an example (a mix of electric arc furnace slag and ladle furnace slag used without control for the pavement subbase) of the consequences of its misuse. 


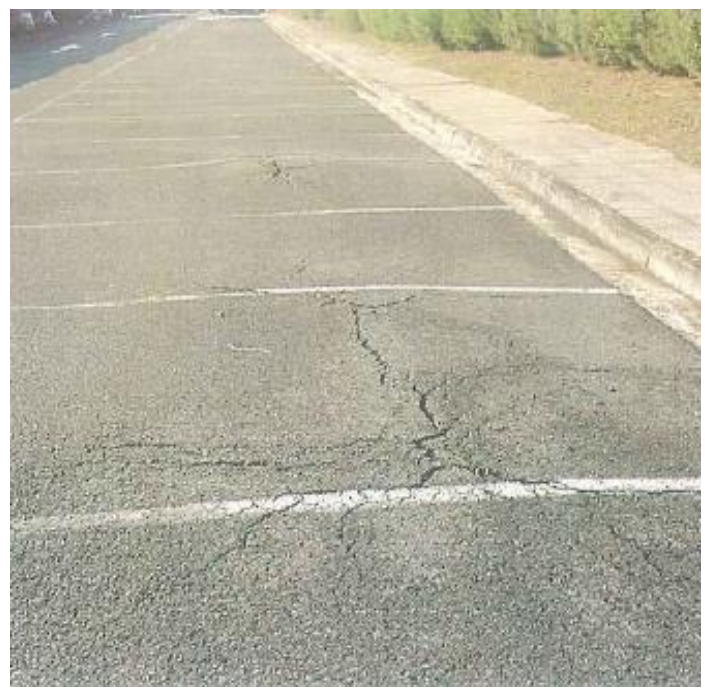

Figure 1: Vitoria airport car-park (2008)

However, researches (Manso, Losañez et al. 2005) has shown that LF slag can be trouble free when used in the right proportion. Other investigations have also demonstrated its slightly hydraulic properties and that it can be used for the stabilization of clayey soils (Ortega-López, Manso et al. 2014), as a filler in bituminous mixes (Skaf, Ortega-López et al. 2016), and as the fine fraction in hydraulic mixes (Sideris, Tassos et al. 2015).

The objective in this work is to test the use of LF slag in replacement of cement. It has been shown that in small proportions (Herrero, Vegas et al. 2016), it could be a suitable SCM. The objective is to analyse the hydraulicity of the Ladle furnace slag and to establish its maximum content in hydraulic mixes.

In this research, a series of mortar mixes will be manufactured with both types of LF slag -alumina-saturated LF slag and silica-saturated LF slag- in replacement of cement, at different proportions, in order to analyse slag hydraulicity and the mechanical properties of the mortar mixes.

\section{MATERIALS}

Portland cement type I 42.5 R, as per standard UNE-EN 197-1 (CEN European Committee for standardization), was used to manufacture all the mixes. Mains water from the urban mains supply of the city of Bilbao was used, containing no compounds with potentially harmful effects on the hydraulic mixes. Likewise, a commercial crushed natural limestone aggregate (size 0-5) was used, the main mineral of which was calcite (95 wt.-\%) with a specific gravity of $2.67 \mathrm{Mg} / \mathrm{m} 3$.

The respective compositions of the two different types of Ladle Furnace Slag -LFSG (alumina saturated) and LFSH (silica saturated)- used in the study are presented in Table 1 . 
Table 1: LS slag chemical composition

\begin{tabular}{|l|c|c|}
\hline Compounds [\%] & LFSH & LFSG \\
\hline $\mathbf{C a O}$ & 59.2 & 50.7 \\
\hline $\mathbf{S i O}_{2}$ & 21.3 & 10 \\
\hline $\mathbf{A l}_{2} \mathbf{O}_{3}$ & 8.27 & 23.3 \\
\hline $\mathrm{MgO}_{3} \mathbf{O}_{3}$ & 7.92 & 13.6 \\
\hline $\mathrm{Fe}_{2} \mathbf{O}_{3}$ & 1 & 0.53 \\
\hline $\mathbf{T i O}_{2}$ & 0.17 & 0.1 \\
\hline $\mathbf{M n O}_{\mathbf{C}}$ & 0.26 & 0.15 \\
\hline $\mathbf{S}$ & 0.13 & 0.2 \\
\hline Others & 1.39 & 0.2 \\
\hline
\end{tabular}

Some of the authors (Ortega-López, Manso et al. 2014) of this paper have also conducted in-depth studies on the main properties of both slag types in earlier works, including accelerated ageing tests to define slag expansiveness. Their results suggested that the expansion of both LFSH and LFSG amounted to $22 \%$ and to $37 \%$, respectively. A detailed description of these two slag types may be found in this research paper.

\section{TEST METHODS}

Mortars were prepared in a conventional standardized mortar-mixer and poured into 40x40x160 mm moulds; four additional specimens were cast per mix of 25x25x285 mm to evaluate shrinkage. They were demoulded after $24 \mathrm{~h}$ and submerged in water, except for the set of specimens used to evaluate dry shrinkage contraction.

A flow table was used to measure the workability of the mortars, as specified in ASTM C230 (ASTM International 2008).

Changes in the strength of the mixes were measured, using the specifications in standards ASTM C-348 and ASTM C-349 (ASTM International 2008). First a flexural test was performed and then the two pieces from each specimen were tested under compression. Variations in length due to shrinkage were measured in accordance with the tests specified in standards ASTM C596-07 and ASTM C490-93 (ASTM International 2008).

The volumetric stability of the mortar mixes was analysed, using an accelerated ageing test that consists of immersion of the specimens in water at $70^{\circ}$ for shrinkage evaluation, as per standard ASTM D4792, and measurement of any changes in length.

\section{DESIGN}

Nine different mortar mixes were designed with the dosages of the mixes detailed in Table 2. All the mixes had the same water/binder ratio $(0.5)$ and the same proportion of 
aggregates with different amounts of cement content. The cement was substituted by both LFSH and LFSG in proportions of $10 \%, 20 \%, 30 \%$ and $40 \%$, to produce eight different mixes. A single reference mix was manufactured with no addition of slag. The superplasticizer dosage was modified to achieve the same workability in all the mixes. It was observed that when the LF slag was added, the workability of the mixes was poorer, so the LF slag mixes needed larger dosages of admixture to achieve the same workability as the reference mix. It was also noted that the mixes manufactured with LFSH needed larger dosages of superplasticier than the mixes manufactured with the same proportion of LFSG.

Table 2: Mix Design

\begin{tabular}{|c|c|c|c|c|c|c|}
$\begin{array}{l}\text { Mix } \\
\text { Design } \\
(\mathrm{kg} / \mathrm{m} 3)\end{array}$ & Cement & LFSH & LFSG & $\begin{array}{l}\text { Limestone } \\
\mathbf{( 0 - 5 m m )}\end{array}$ & $\begin{array}{l}\text { Water/binder } \\
\text { ratio [\%] }\end{array}$ & $\begin{array}{l}\text { Superplasticizer } \\
\text { [\% binder] }\end{array}$ \\
\hline M0 & 513 & 0 & 0 & 1540 & 0.5 & 1.20 \\
\hline MH10 & 462 & 51 & 0 & 1540 & 0.5 & 1.25 \\
\hline MH20 & 410 & 103 & 0 & 1540 & 0.5 & 1.35 \\
\hline MH30 & 359 & 154 & 0 & 1540 & 0.5 & 1.40 \\
\hline MH40 & 308 & 205 & 0 & 1540 & 0.5 & 1.40 \\
\hline MG10 & 462 & 0 & 51 & 1540 & 0.5 & 1.25 \\
\hline MG20 & 410 & 0 & 103 & 1540 & 0.5 & 1.25 \\
\hline MG30 & 359 & 0 & 154 & 1540 & 0.5 & 1.30 \\
\hline MG40 & 308 & 0 & 205 & 1540 & 0.5 & 1.30 \\
\hline
\end{tabular}

\section{RESULTS AND DISCUSSION}

\section{Workability}

As detailed in table 2, all the mixes were designed to achieve the same workability: spontaneous spreading of $170 \pm 3 \mathrm{~mm}$ on the flow table. The need to use larger dosages of superplasticizer in the mixes that included slag as a binder is evident, which underlines the higher water absorption of the LF slag particles in comparison with the cement particles. The fact is that even though both materials absorb water, larger quantities of water are drawn into the slag particles, because of their external capillarity. As mentioned above in the introduction, the slag particle are single polyhedral crystals or irregular aggregates formed of hollow polyhedral crystals. When the aggregates containing polyhedral crystals come into contact with water, capillary action draws the water inwards, filling the hollow spaces. 


\section{Density}

The densities of the nine mortar mixes were very similar, in all cases approximately 2.3 $\mathrm{Mg} / \mathrm{m}^{3}$, which might be expected in view of the similar densities of cement $\left(3.1 \mathrm{Mg} / \mathrm{m}^{3}\right)$ and LF slag $\left(3.03 \mathrm{Mg} / \mathrm{m}^{3}\right)$.

\section{Compressive Strength}

The changes in the compressive strength of the mixes are shown in Figure 2. The reference mortar shows the highest strength; M0 reached 72MPa. Mixes MH10, MH20, and MH30 showed good mechanical behaviour, the loss of strength was $8 \%, 16 \%$ and $26 \%$, respectively, which are acceptable values considering the levels of cement replacement. In the case of mix MH40, the decrease in its compressive strength was very pronounced, $46 \%$ lower than the reference mix, and 27\% lower compared with MH30, so it appears that, in this case, the use of silica saturated ladle furnace slag in proportions higher than $30 \%$ was not convenient.

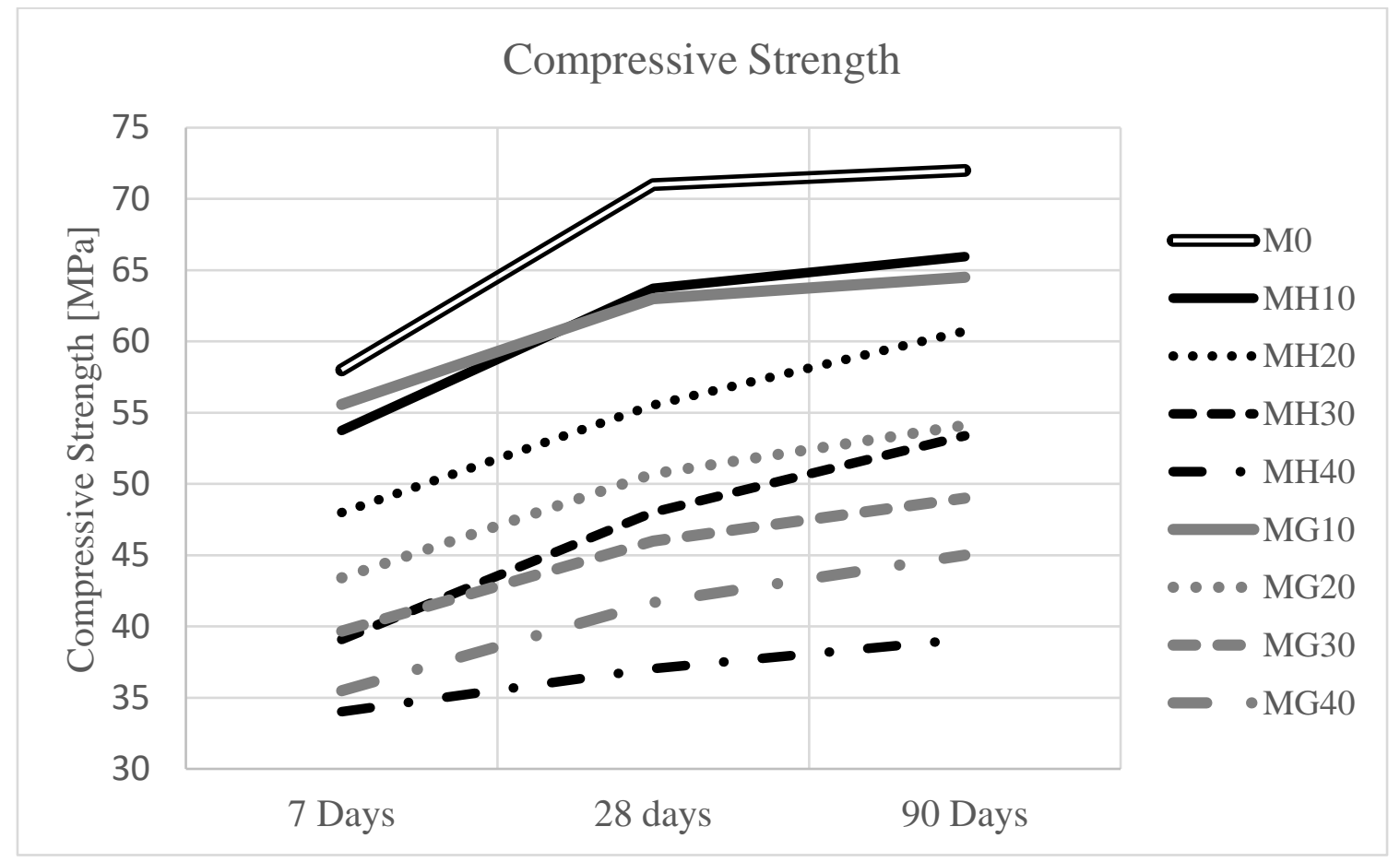

Figure 2: Compressive strength of mixes

The loss of compressive strength of the mixes MG10, MG20, MG30 and MG40 was higher in comparison with the $\mathrm{MH}$ mixes with the same proportions of cement 
replacement, with the exception of mix MG40. In this case, the loss of compressive strength amounted to $10 \%, 25 \%, 32 \%$, and $37 \%$, respectively.

It is worth asking whether the strength of the mixes with $20 \%, 30 \%$ and $40 \%$ of cement replaced by slag had actually reached their maximum strengths. The evolution of the strength of these mixes between 28 and 90 days was high (3-5MPa), compared with the evolution of the strength of mixes M0, MH10 and MG10 over the same period (1-2MPa). So, the replacement of cement by silica saturated ladle furnace slag at levels of $30 \%$ are "a priori" highly recommended in terms of mechanical strength. The mechanical behaviour of hydraulic mixes with alumina saturated ladle furnace slag showed poorer compressive strengths, at least at early ages. However, the long-term mechanical behaviour (180-365 days) of the mixes with percentage replacements of over $20 \%$ should also be studied.

\section{Length Variation}

The length variation of the specimens was measured in two different states; four specimens of each mix were manufactured with that purpose in mind. Two of the specimens were kept submerged in water, and the other two specimens were submerged in water over the first 3 days and then under atmospheric conditions in the same chamber at room temperature.

Figure 3 details the changes in length of all the mixes. The lengths of the specimens were recorded in a rigid frame equipped with precision measurement instruments.

The upper set of values refers to the specimens held in water. In this case, the aim was to monitor excessive expansion, due to the reactions of free lime and free magnesia. Nevertheless, the behaviour of all the mixes proved similar, reaching approximate values of $0.2 \mathrm{~mm} / \mathrm{m}$. 


\section{Length Variation}

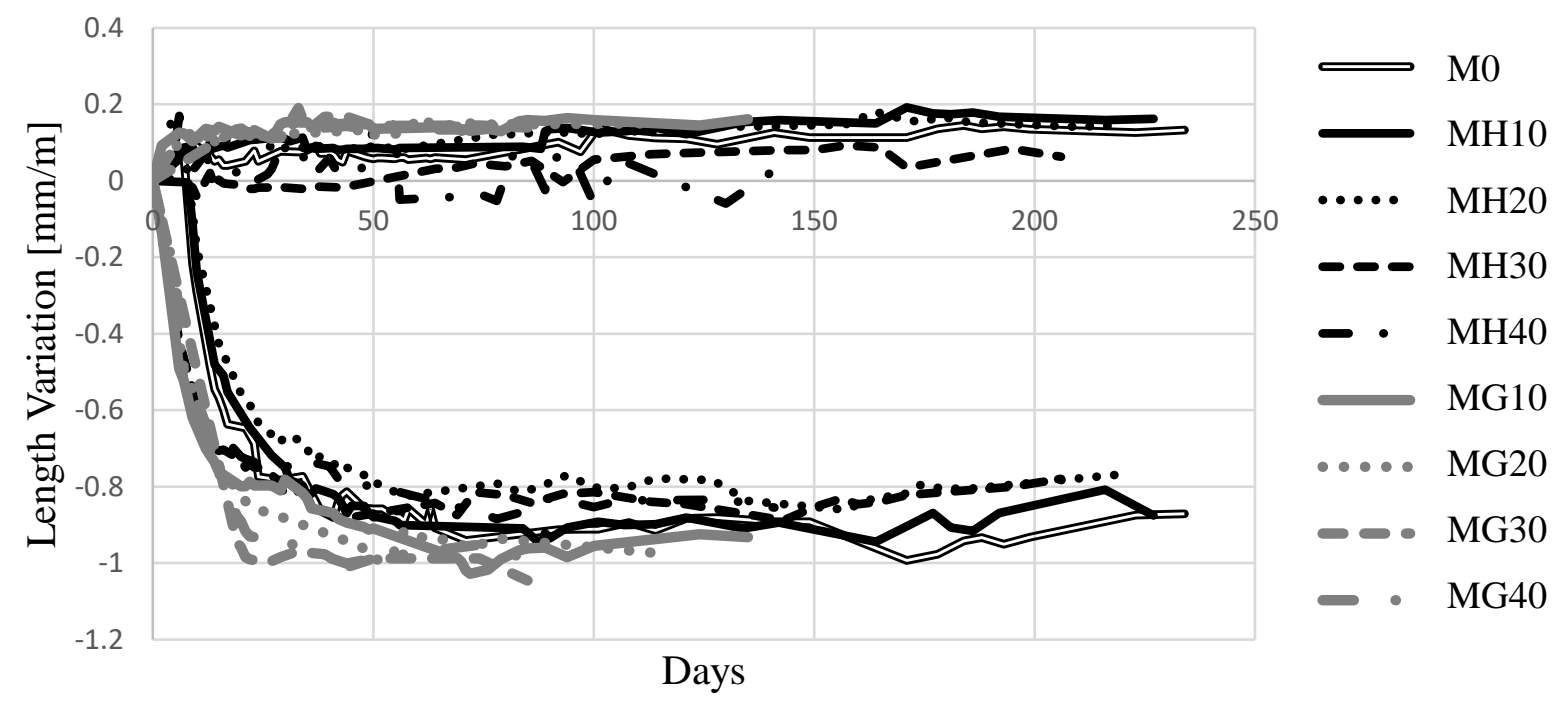

Figure 3: Length variation of mortar mixes

The shrinkage contraction of all the specimens was also very similar; all the values were between $-0.8 \mathrm{~mm} / \mathrm{m}$ and $-1 \mathrm{~mm} / \mathrm{m}$. However, in this case it can be observed that the specimens manufactured with LFSH showed less contraction than the reference mortar (M0). Likewise, all the specimens manufactured with LFSG showed higher contraction rates than the reference mix. All the mortars therefore showed good shrinkage behaviour, especially the mortars manufactured with LFSH.

\section{Accelerated Ageing Test}

Having completed the shrinkage test on the mortar specimens, two of the specimens used in that test were submerged in water at $70^{\circ}$ for one month.

The test serves to evaluate possible damage caused by the expansive compounds (Free lime and Free Magnesia) of the LF slag in the mortar specimens. As previously stated, the use of this slag without proper supervision can cause damage in the manufactured element, as has been seen in the past. Hence, the imperative need to establish a maximum content of LF slag that will not influence any decrease in the durability of the building component. In Table 3, the data on the final expansion of the specimens is shown, following immersion in water at $70^{\circ}$ for one month. Total expansion of the reference mix, M0, with no expansive compounds, amounted to $0.72 \mathrm{~mm} / \mathrm{m}$. Mixes with percentage replacement of cement at $10 \%, 20 \%$ and $30 \%$ by any slag type showed very encouraging expansion values similar to (or even lower than) the reference mix. 
Table 3: Specimen expansion after immersion in water at $70^{\circ}$ over one month

\begin{tabular}{|c|c|}
\hline & Expansion $[\mathrm{mm} / \mathrm{m}]$ \\
\hline M0 & 0.72 \\
\hline MH10 & 0.68 \\
\hline MH20 & 0.71 \\
\hline MH40 & 0.64 \\
\hline MG10 & 0.97 \\
\hline MG20 & 0.63 \\
\hline MG30 & 0.65 \\
\hline MG40 & 0.63 \\
\hline
\end{tabular}

In both cases, the expansion of the specimens was significantly higher with the incorporation of $40 \% \mathrm{LF}$ slag, especially in the case of MG40, which reached an expansion value of $1.6 \mathrm{~mm} / \mathrm{m}$, more than double the reference mix.

To sum up, on the basis of the results in this research work, LS slag in replacement of cement is not recommendable at levels higher than $30 \%$, regardless of whether the slag is either silica or alumina saturated.

\section{CONCLUSIONS}

In this study, the use of Ladle Furnace slag as an active addition in replacement of Portland cement has been studied. Further investigations will be needed to continue evaluating the behaviour of LF slag in these concrete designs. Nevertheless, according to the experimental results obtained in this work, the following conclusions can be drawn:

- The use of Ladle Furnace slag in mortars decreases the workability of the mixes, especially in the case of silica-saturated Ladle Furnace slag. Nevertheless, it is easy to produce mixes with a similar workability to reference mortars by increasing the dosage of superplasticizers.

- When LF slag was used in replacement of cement, there was in all cases a decrease in the compressive strength of the specimens. However, the mechanical behaviour of the mixes manufactured with silica-saturated LF slag was acceptable, up to levels of $30 \%$.

- No significant shrinkage behaviour of the mortars specimens was noted, not even during the development of the test. Both the specimens incorporating LFS in replacement of cement and the reference mortar showed similar variations. 
- The expansion values of the mortar, after the immersion of the specimens in water at $70^{\circ}$ over one month, suggest that the replacement of cement by either type of LF slag at levels of over $30 \%$ could have detrimental consequences, especially in the case of alumina-saturated LF slag.

\section{AKNOWLEDGMENTS}

The authors wish to express their gratitude for the financing of this research to: Junta de Castilla y León (Regional Government) for funding UIC-231 through project BU119P17; the National Spanish Government through the Ministry of Science, Innovation and Universities; the Basque Government for funding research group IT71813, and IT1314-19; and FEDER (European Regional Development Funds). Moreover, we are grateful to Josu San Sebastian for his help during the experimental campaign.

\section{REFERENCES}

CEN European Committee for standardization. Rue de Stassart, 36. Brussels B-1050.

ASTM INTERNATIONAL, 2008. Annual book of ASTM standards. West Conshohocken, 19429-2959. PA, USA.

FALESCHINI, F., HOFER, L., ZANINI, M.A., DALLA BENETTA, M. and PELLEGRINO, C., 2017. Experimental behavior of beam-column joints made with EAF concrete under cyclic loading. Engineering Structures, 139, pp. 81-95.

FELEKOGLU, B., TOSUN, K., BARADAN, B.+., ALTUN, A. and UYULGAN, B., 2006. The effect of fly ash and limestone fillers on the viscosity and compressive strength of self-compacting repair mortars. Cement and Concrete Research, 36(9), pp. 1719-1726.

GARCÍA MOCHALES, J.L., 2016. Utilización de áridos siderúrgicos en obras por la autoridad portuaria de Bilbao. ekosteguna: ihobe.

GÜNEYISI, E., GESOĞLU, M., ALTAN, İ and ÖZ, H.Ö, 2015. Utilization of cold bonded fly ash lightweight fine aggregates as a partial substitution of natural fine aggregate in self-compacting mortars. Construction and Building Materials, 74, pp. 916. 
HERRERO, T., VEGAS, I.J., SANTAMARÍA, A., SAN-JOSÉ, J.T. and SKAF, M., 2016. Effect of high-alumina ladle furnace slag as cement substitution in masonry mortars. Construction and Building Materials, 123, pp. 404-413.

MANSO, J.M., LOSAÑEZ, M., POLANCO, J.A. and GONZALEZ, J.J., 2005. Ladle furnace slag in construction. Journal of Materials in Civil Engineering, 17(5), pp. 513518.

ORTEGA-LÓPEZ, V., MANSO, J.M., CUESTA, I.I. and GONZÁLEZ, J.J., 2014. The long-term accelerated expansion of various ladle-furnace basic slags and their soilstabilization applications. Construction and Building Materials, 68, pp. 455-464.

SETIÉN, J., HERNÁNDEZ, D. and GONZÁLEZ, J.J., 2009. Characterization of ladle furnace basic slag for use as a construction material. Construction and Building Materials, 23(5), pp. 1788-1794.

SIDERIS, K.K., TASSOS, C. and CHATZOPOULOS, A., 2015. Production of Durable Self-compacting Concrete Using Ladle Furnace Slag (LFS) as Filler Material. Procedia Engineering, 108, pp. 592-597.

SKAF, M., ORTEGA-LÓPEZ, V., FUENTE-ALONSO, J.A., SANTAMARÍA, A. and MANSO, J.M., 2016. Ladle furnace slag in asphalt mixes. ??, pp. ?? 